\title{
WRF Hindcasts of Cold Front Passages over the ARM Eastern North Atlantic Site: A Sensitivity Study
}

\author{
FAYÇAL LAMRAOUI AND JAMES F. BOOTH \\ City College of the City University of New York, New York, New York \\ CATHERINE M. NAUD \\ Applied Physics and Applied Mathematics, Columbia University, and NASA Goddard Institute for \\ Space Studies, New York, New York
}

(Manuscript received 27 September 2017, in final form 28 May 2018)

\begin{abstract}
The present study explores the ability of the Weather Research and Forecasting (WRF) Model to accurately reproduce the passage of extratropical cold fronts at the DOE ARM eastern North Atlantic (ENA) observation site on the Azores. An analysis of three case studies is performed in which the impact of the WRF domain size, position of the model boundary relative to the ENA site, grid spacing, and spectral nudging conditions are explored. The results from these case studies indicate that model biases in the timing and duration of cold front passages change with the distance between the model domain boundary and the ENA site. For these three cases, if the western model boundary is farther than $1500 \mathrm{~km}$ from the site, the front becomes too meridional and fails to reach the site, making 1000 or $1500 \mathrm{~km}$ the optimal distances. In contrast, integrations with small distances (e.g., $500 \mathrm{~km}$ ) between the site and domain boundaries have inadequate spatial spinup (i.e., the domain is too small for the model to properly stabilize). For all three cases, regardless of domain size, the model has biases in its upper-level circulation that impact the position and timing of the front. However, this issue is most serious for $4000-\mathrm{km}^{2}$ domains and larger. For these domains, prolonged spectral nudging can correct cold front biases. As such, this analysis provides a framework to optimize the WRF Model configuration necessary for a realistic hindcast of a cold front passage at a fixed location centered in a domain as large as computationally possible.
\end{abstract}

\section{Introduction}

According to the reports of the Intergovernmental Panel on Climate Change (IPCC), clouds and their feedback are among the prevailing uncertainties in weather and climate models (IPCC 2013). Despite the advances in the modeling community to improve cloud representation (e.g., Medeiros et al. 2008; Mioche et al. 2015; Bretherton et al. 2004), issues with cloud parameterization persist in both numerical weather prediction (NWP; e.g., Janowiak et al. 2007) and climate models (e.g., Field et al. 2008; Naud et al. 2010). In particular, moist convection, shallow convection, and their impacts on cloud formation are still inadequately represented in the general circulation models (GCMs; e.g., Jakob 2010; van Stratum and Stevens 2015). In recent years, it has emerged that midlatitude clouds in

Corresponding author: Fayçal Lamraoui, faycal.lamraoui@gmail. com the storm track regions might impact the response of the atmosphere to anthropogenic climate change (Voigt and Shaw 2015), and most GCMs underestimate cloud amount over the midlatitude oceans (Trenberth and Fasullo 2010). The latter issue causes an excess of shortwave absorption at the ocean surface in the Southern Hemisphere summer. This cloud bias affects most GCMs of the CMIP5 and was found to occur within extratropical cyclones (Bodas-Salcedo et al. 2012), with the largest bias in the cold sector, to the west of the low pressure center of the cyclones, in the post-cold-frontal region (Bodas-Salcedo et al. 2014). Even reanalyses exhibit this bias (Naud et al. 2014).

Motivated by the need to understand low-level clouds located in post-cold-frontal regions, we intend to use a regional, high-resolution model to explore the physical parameterizations that are important for cloud representation in these synoptic conditions. However, before we can consider the modeled clouds, the model needs to 
generate the correct synoptic conditions. Given that a regional model's physics can be sensitive to the domain configuration (Giorgi and Mearns 1999; Stevens et al. 2005), the present work uses the Weather Research and Forecasting (WRF) Model to identify the optimal domain size for an adequate reproduction of three specific cold front passages.

Numerous studies have addressed the sensitivity to model grid spacing and driving lateral boundary conditions (e.g., Stevens et al. 2005). Domain size also plays an important role in the balance between the boundary forcing and internal model physics (Giorgi and Mearns 1999). Large domains can lead to uncertainty in a regional climate model due to the lack of control from the boundary conditions, but small domains can exclude important large-scale processes (e.g., Stevens et al. 2005). Also, the presence of strong forcings, such as those associated with an extratropical cyclone, is challenging to mesoscale development (Treadon and Petersen 1993), and the large gradients and accelerations are not adequately handled by the lateral boundary conditions. Therefore, for smaller domains, the errors can propagate rapidly to the domain interior (Warner et al. 1997). Studies have demonstrated the influence of the domain size on model dynamics (Skamarock 2004), turbulence intensity (Yamaguchi et al. 2013), shallow cumulus convection (Stevens et al. 2002), stratocumulus clouds (de Roode et al. 2004), cloud structure and their statistical characteristics (Wood 2012), low marine clouds (Wood and Hartmann 2006), tropical heavy rain (Goswami et al. 2012), monsoon season (Qian and Zubair 2010), and large-eddy simulation of the stratocumulus-topped boundary layer (Pedersen et al. 2016). Furthermore, domain size, grid spacing, and lateral boundary conditions are comparably important for dynamical downscaling (Xue et al. 2007). Therefore, the current work is aimed at establishing the limitations in spatial domain needed to generate the synoptic circulation of post-cold-frontal regions in a regional model.

The work herein focuses on cold fronts passing over Graciosa Island at the eastern North Atlantic site (ENA; $39.088^{\circ} \mathrm{N}, 28.018^{\circ} \mathrm{W}, 15.24-\mathrm{m}$ elevation). The ENA site is a fixed routine measurements facility of the U.S. Department of Energy (DOE) Atmospheric Radiation Measurement (ARM) program that offers ground-based observations of meteorology, aerosols, and clouds. The facility was initially set up as part of a field campaign: Clouds, Aerosol, and Precipitation in the Marine Boundary Layer (CAP-MBL; Wood et al. 2015). This location is found near, and oftentimes beneath, the subtropical Azores high-pressure system. It is subject to midlatitude cold-air outbreaks, including those that follow cold frontal passages, which are favorable to the formation of low marine boundary layer clouds. Thus, the ENA site represents a prime location to study marine stratocumulus and shallow cumulus regimes under the influence of midlatitude storms (Rémillard et al. 2012; Rémillard and Tselioudis 2015).

To achieve our objective of understanding the sensitivity of the simulated cold frontal passage to model configuration, a series of WRF simulations are conducted in domains encompassing the ENA site for three case studies. The modeled results are compared to the ENA ground observations to examine the impact of domain size and geographical orientation on the correct representation of a cold front passage at a fixed location in a maritime environment.

\section{Methodology}

\section{a. Identification of cold front passages over the ENA site}

The observations from the ENA site that are used in this study are those from radiosondes for profiles of wind, dry and dewpoint temperatures (ARM 1993), and the meteorological station that includes surface pressure, 2-m relative humidity and temperature, and 10-m wind direction and speed (ARM 2013). A technical description of the sensors is available on the ARM website (www.arm.gov).

The first step of the study is to identify three cases of cold front passages at the ENA site. To start, we use the cold front database developed in Naud et al. (2016) to flag dates when a cold front is detected near the site. This database was developed using an automated detection routine applied to the Modern-Era Retrospective Analysis for Research and Applications, version 2 (MERRA2; Gelaro et al. 2017), surface and 850-hPa winds and temperature gradients $1 \mathrm{~km}$ above the surface. We refer the reader to Naud et al. (2016) for more details and examples. This database is 6 hourly, so although it helps flag dates, it does not give a precise time of the frontal passage at the site, nor can it indicate the duration of post-cold-frontal conditions. To get this information, we use the wind direction time series from the ENA meteorological station: wind direction changes from southerly to northerly with the frontal passage, and this change is instantaneous. Therefore, on the days with a cold front passage detection at the ENA site, we use a 60-min running window average of the 1-min wind direction observations and identify the change in wind direction from southerly to northerly to mark the time of the frontal passage. We use the opposite change at a later time to mark the end of the post-cold-frontal conditions. More details and a list of cases are available in Naud et al. (2018, submitted to J. Geophys. Res. Atmos.). 


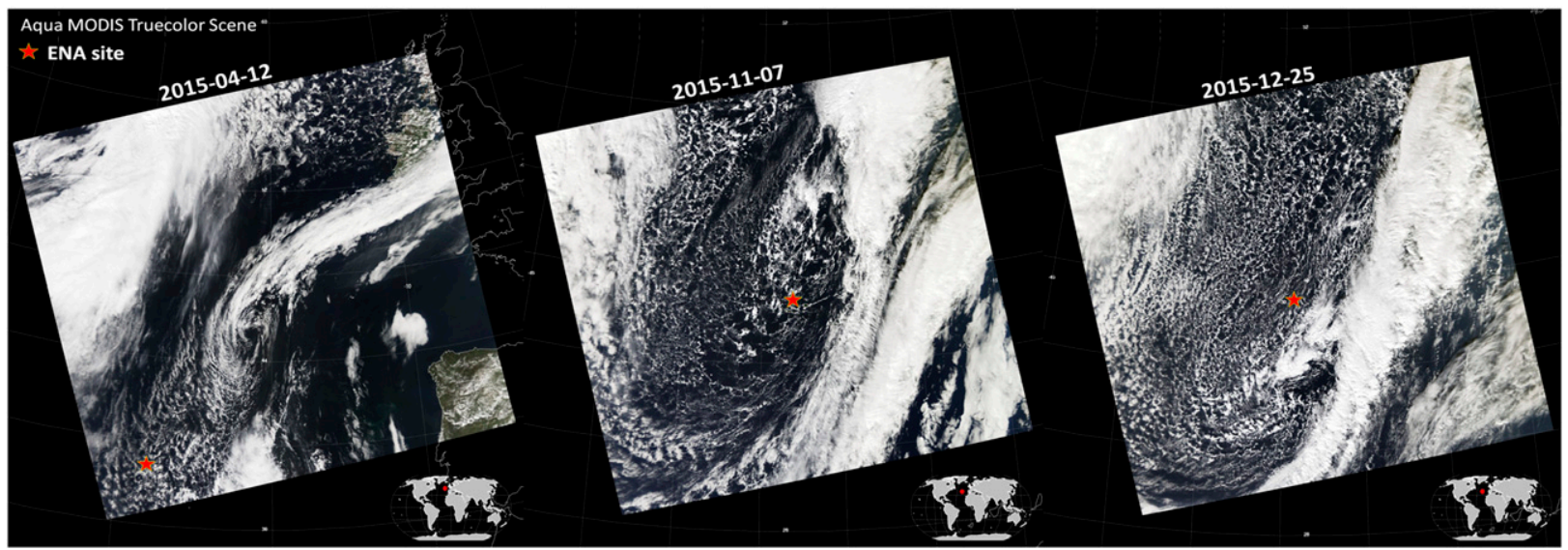

FIG. 1. MODIS Aqua true-color images of Azores post-cold-frontal scenes acquired at (left) 1420 UTC 12 Apr, (middle) 1500 UTC 7 Nov, and (right) 1500 UTC 25 Dec 2015, approximately 26, 3, and $18 \mathrm{~h}$ after the cold front passage, respectively. The red dot marks the Azores embedded within the post-cold-frontal region. (True-color images courtesy of https://modis-atmos.gsfc.nasa.gov/IMAGES/index.html.)

We chose three cases, the cloud fields for which were all documented by the NASA Moderate Resolution Imaging Spectroradiometer (MODIS; Salomonson et al. 1989) on board the Aqua platform (Fig. 1). Cold fronts occur at the ENA site preferably during the cold season, so the cases were chosen as representatives of the winter, spring, and fall.

\section{b. Numerical setup}

The simulations of the three case studies of cold front passages examined here were performed using WRF-ARW Model version 3.8.1 (Skamarock et al. 2008). The timing choice of each case corresponds to the passage of cold fronts over the ENA site observed from surface-based measurements of wind speed and direction. The first case study is a 72-h integration from 0000 UTC 24 December to 0000 UTC 27 December 2015 (hereafter referred as the December case). The two additional cases are an 84-h integration from 0000 UTC 11 April to 1200 UTC 14 April 2015 (hereafter referred to as the April case) and a 72-h integration from 0000 UTC 6 November to 0000 UTC 9 November 2015 (hereafter referred to as the November case).

The simulations were initiated using $0.75^{\circ}$ grid spacing ERA-Interim fields every $6 \mathrm{~h}$ and 37 vertical pressure levels (Dee et al. 2011). The ERA-Interim is widely used, and it compares better to observations in data-sparse regions, compared to other reanalysis products (e.g., Lindsay et al. 2014). The three case studies were tested with the same horizontal grid spacing of $20 \mathrm{~km}$ using six domain sizes of $50 \times 50,100 \times 100,150 \times 150,200 \times 200,250 \times$ 250 , and $300 \times 300$ grid points centered on the ENA site (Fig. 2). Given the reanalysis grid spacing $(81 \mathrm{~km})$, the horizontal grid spacing of $20 \mathrm{~km}$ (which gives a downscaling ratio of approximately 1:4) was chosen to limit storage and computational costs. The impact of this choice of downscaling ratio on our results will be discussed below. The numerical experiments were performed with the same temporal resolution of $d t=120 \mathrm{~s}$, and the output is stored every $30 \mathrm{~min}$. All cases use 41 vertical levels with a grid spacing of $d z=50 \mathrm{~m}$ near the surface and gradually larger $d z$ values with height upward. Beyond the vertical level of $\sim 3000 \mathrm{~m}$, the vertical grid spacing is constant: $d z=$ $608 \mathrm{~m}$ until the highest level of $20 \mathrm{~km}$.

The cloud parameterization used in all simulations is the double-moment cloud microphysics scheme (Morrison 2-moment), which predicts the mixing ratios and number concentrations of five hydrometeors (Morrison et al. 2009). The longwave radiation physics is represented by the Rapid Radiative Transfer Model (RRTM; Mlawer et al. 1997), and shortwave physics is represented by the Dudhia shortwave scheme (Dudhia 1989). The surface layer and land surface were simulated using the revised MM5 Monin-Obukhov scheme (Jiménez et al. 2012) and the unified Noah land surface model (Tewari et al. 2004), respectively. For the parameterization of the planetary boundary layer (PBL) physics, the Yonsei University (YSU) PBL scheme (Hong et al. 2006) was implemented. This PBL scheme is an updated version of the previous Medium-Range Forecast (MRF) scheme (Hong and Pan 1996). Both schemes come with a nonlocal turbulent mixing coefficient in the planetary boundary layer. The revised version of vertical diffusion includes an explicit treatment of entrainment at the top of the PBL and corrects systematic biases of the large-scale features detected in the MRF PBL. The latest version of the KainFritsch scheme (Kain 2004) was employed for physical parameterization of cumulus clouds. 


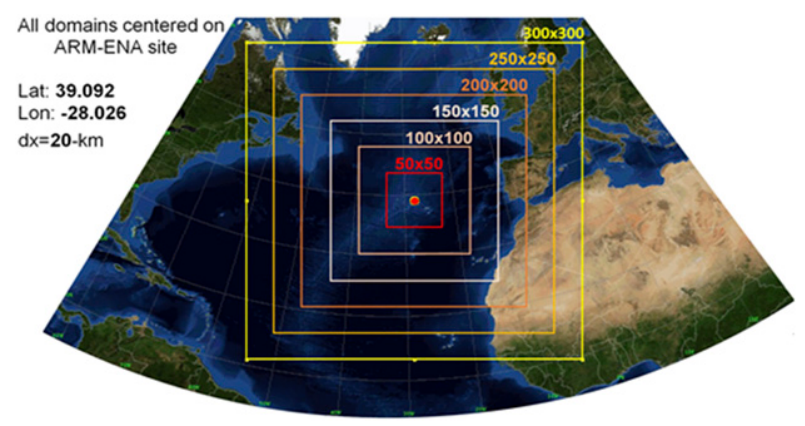

FIG. 2. The six simulation domains chosen for this study, all centered on the ARM-ENA site (red dot) on Graciosa Island (Portugal; $39^{\circ} \mathrm{N}, 28^{\circ} \mathrm{W}$ ). The legend in the top-right corner of each domain represents the number of grid points.

To be consistent with observations, the simulated wind speed and wind direction are derived from the direct extraction of WRF U10 (zonal wind velocity $10 \mathrm{~m}$ above ground), and V10 (meridional wind velocity $10 \mathrm{~m}$ above the ground). The temporal resolution of the instantaneous model output is $30 \mathrm{~min}$. Similar to the identification of the cold front passage in the observations, the change in the simulated wind direction from southerly to northerly is used to identify the passage of the simulated cold front passage.

\section{Results and discussion}

The results are presented first for the case study from December because it occurred during the season when cold fronts are most frequent at the ENA site. The case studies from spring (April) and fall (November) are included to verify the results obtained with the December case.

\section{a. Description of the December case simulations}

Because a strong gradient in integrated atmospheric water vapor is a good tracer of the cold front location in satellite data (e.g., Kanaros et al. 1989), we first explore the distribution of the precipitable water $(\mathrm{PW})$ derived from ERA-Interim, WRF $150 \times 150$ domain size, and WRF $300 \times 300$ domain size (Fig. 3). At 0000 UTC 25 December 2015 (i.e., $24 \mathrm{~h}$ after the start of the simulation), the reanalysis and the WRF $150 \times 150$ simulation both have a large PW gradient over the ENA, oriented southwest to northeast (Figs. 3a,b). The larger $300 \times 300$ simulation displays a weak PW gradient that is more zonally oriented and does not reach the ENA site (Fig. 3c). In the $150 \times 150$ domain, the front has a stronger north-south component than the reanalysis, indicating that it is not a perfect simulation. But as we show below, this bias has only a minor impact on the simulation of the cold frontal passage, especially in comparison to the largest $(300 \times 300)$ and smallest $(50 \times 50)$ domain-size integrations.

The $300 \times 300$ domain generates a cold front, but it never reaches the ENA site. This is due to the bias in the spatial orientation of the front that was just discussed (Fig. 3c). Consistent with this issue, there is considerable bias in the spatial distribution of surface pressure in the $300 \times 300$ domain simulation: the model either does not generate a deep enough low pressure system northeast of the cold front, or it does so too far to the west of the site (Fig. 4a).

A comparison of the reanalysis and model time evolution of SLP at the ENA site indicates that all of the simulations have some bias (Fig. 4b). The $200 \times 200$ and $300 \times 300$ domain sizes show no signs of deepening during the integration time. The smaller domains indicate occurrences of deepening, but for each model

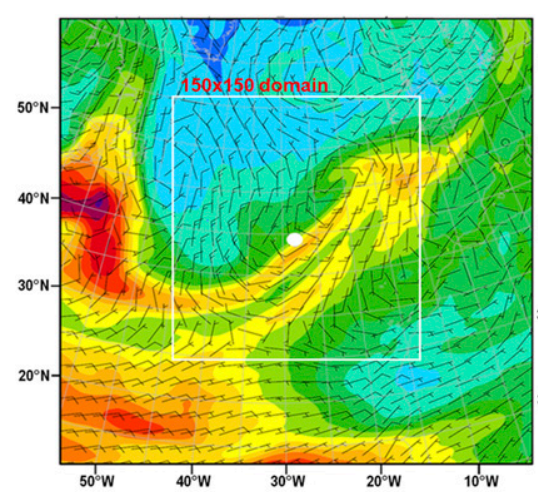

(a) ERA-Interim : (dx 81- $\mathrm{km})$

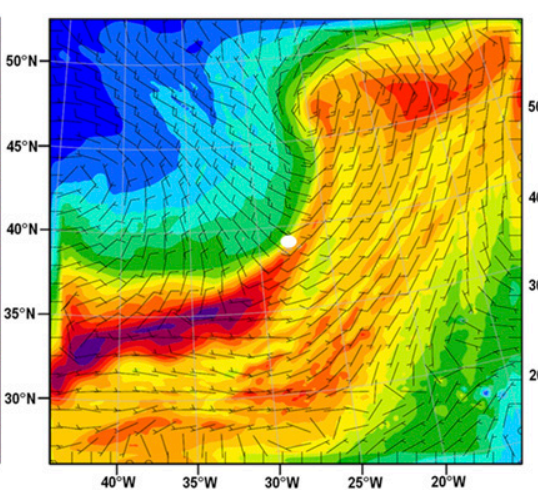

(b) WRF : Domain 150x150 (dx=20-km)

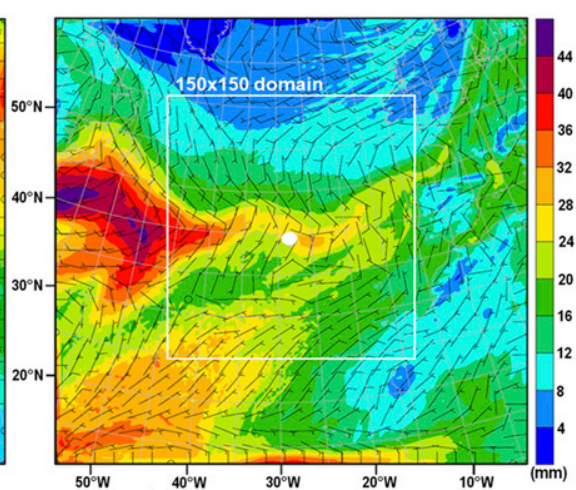

(c) WRF : Domain $300 \times 300(\mathrm{dx}=20-\mathrm{km})$

FIG. 3. Two-dimensional distributions of the precipitable water from (a) ERA-Interim, (b) WRF $150 \times 150$, and (c) WRF $300 \times 300$ domain sizes, centered on the ENA site (white dot) for the December case (0000 UTC 25 Dec 2015). Note that (b) uses a different grid scale than (a),(c). 

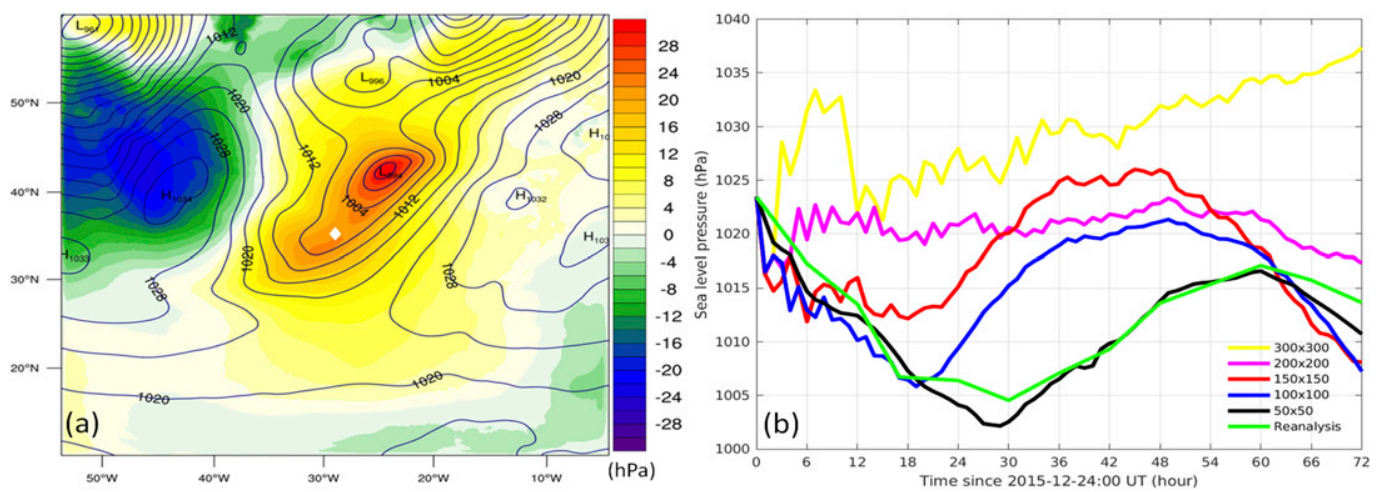

FIG. 4. (a) The difference in sea level pressure between the WRF $300 \times 300$ domain size and ERA-Interim (shaded) centered at the ENA site (white diamond), and the sea level pressure from the reanalysis (contour) at 0000 UTC 25 Dec 2015, and (b) time series of the simulated sea level pressure at the ENA site from the WRF $300 \times 300$ (yellow), $200 \times 200$ (purple), $150 \times 150$ (red), $100 \times 100$ (blue), and $50 \times 50$ (black) domain sizes and the reanalysis (green).

configuration, the deepening occurs at different times. The $50 \times 50$ model agrees most closely with the reanalysis. However, as we will show below, the $50 \times 50$ model has biases in its representation of the cold frontal passage.

Given that a domain size of $200 \times 200$ or larger does not reproduce the cold front passage, the following analyses focus on the evolution of the simulated cold front passage obtained with the $50 \times 50,100 \times 100$ and $150 \times 150$ domain sizes. The observations and the $200 \times 200$ domain size are added for comparison purposes when necessary.

A cold front passage is always associated with a decrease in temperature and air pressure, as well as a pronounced directional wind shear. The observations of wind speed and direction (Fig. 5, first row) indicate that the cold front reaches Graciosa Island at 2054 UTC 24 December 2015 and is fully past at about 0000 UTC 25 December 2015 . The wind direction remains northerly

December Case
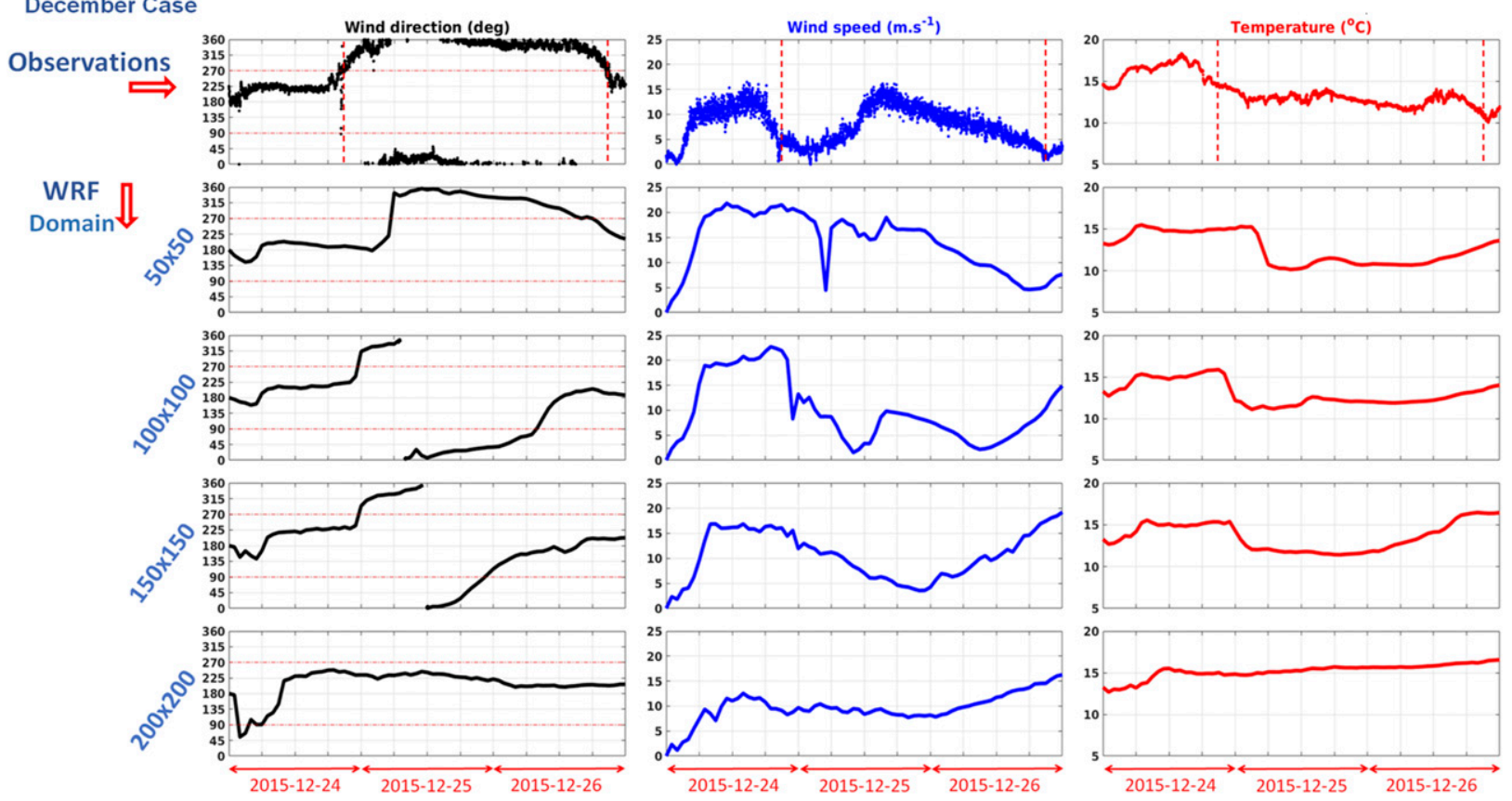

FIG. 5. Time series of (top row) observed and (rows 2-5) simulated (left) wind direction, (middle) wind speed, and (right) temperature at the ENA site for the December 2015 case. The vertical red dashed lines mark the duration of the postfrontal period, and the horizontal dotted lines in the left column mark the $270^{\circ}$ and $90^{\circ}$ wind direction. 
until late 26 December 2015. During the passage of the cold front, the wind speed is rather low, around $5 \mathrm{~m} \cdot \mathrm{s}^{-1}$, and then increases gradually to reach values of about $15 \mathrm{~m} \cdot \mathrm{s}^{-1}$ at around 1800 UTC 25 December 2015. The temperature over the site shows a simultaneous response to the cold front passage and drops from $18^{\circ}$ to $12^{\circ} \mathrm{C}$ (Fig. 5, top row).

The smaller domain sizes capture a cold front passage, but they have varying degrees of success (Fig. 5, rows $2-4)$. The instantaneous switch in wind direction from southerly to northerly that marks the arrival of the cold front at the site in the $50 \times 50$ domain size (Fig. 5, row 2, first column) occurs approximately $12 \mathrm{~h}$ after that observed. For $100 \times 100$ and $150 \times 150$ domain sizes, the delay in the change of wind direction is much smaller, approximately $3 \mathrm{~h}$. This delay is partially associated with the front being more meridional (Fig. $3 \mathrm{~b}$ for the $150 \times$ 150 case). The post-cold-frontal period is defined by the overall northerly winds regime that starts at the time of the cold front passage and in the observations ceases after about $48 \mathrm{~h}$, with a rather rapid return to southerly winds. The simulations generate the abrupt change at the beginning, but at the end, the change in wind direction is more gradual. The $100 \times 100$ domain size simulates a northerly wind for a longer time period, which makes this domain size the most realistic.

The simulated wind speeds show higher values (up to $20 \mathrm{~m} \cdot \mathrm{s}^{-1}$ ) than the observations before the cold front passage (Fig. 5, second column). However, at the time of the cold front passage and during the few hours following it, the wind speed for the $100 \times 100$ and $150 \times 150$ domain sizes are around $10 \mathrm{~m} \cdot \mathrm{s}^{-1}$, which is comparable to the observations. In contrast, the smallest $50 \times$ 50 domain-size wind speed remains higher and fluctuates around $15 \mathrm{~m} \cdot \mathrm{s}^{-1}$ for the entire day on 25 December 2015. The simulated temperature evolution (Fig. 5, third column) corroborates the time lag associated with the $50 \times 50$ domain size and the consistency for the $100 \times$ 100 and $150 \times 150$ domain sizes. The $50 \times 50$ domain size has the most significant temperature decrease of $5^{\circ} \mathrm{C}$, in comparison with the $100 \times 100$ and $150 \times 150$ domain sizes that show an approximate drop of $2^{\circ}$ and $3^{\circ} \mathrm{C}$, respectively, and are a closer match to observations.

This analysis of the temperature and wind changes shows that the $50 \times 50$ domain has larger biases in capturing the frontal passage than the $100 \times 100$ and $150 \times 150$. We attribute this issue to a lack of space (and therefore time) for the forcing from the lateral boundary conditions to converge toward WRF's stable solution. The evolution of the simulated temperature indicates that only the $150 \times 150$ domain size maintains its low temperature until the end of the observed post-coldfrontal period. Because of our overarching interest in the clouds in the post-cold-frontal region, this domain size performs best for the temperature evolution simulation.

Now that we have examined what happens at the surface, we next explore the vertical structure of the model runs using skew $T-\log p$ diagrams. For the site, radiosoundings are available approximately $8.5 \mathrm{~h}$ before (1130 UTC 24 December 2015), right after (2330 UTC 24 December 2015), and $14 \mathrm{~h}$ after (1131 UTC 25 December 2015) the passage of the cold front. For comparison, we generate the same diagrams using simulated temperature and dewpoint temperature profiles closest in time to the observations for the $50 \times 50,100 \times 100$, and $150 \times 150$ domain sizes.

Prior to the arrival of the cold front, the observations (Fig. 6a) indicate an inversion near $800 \mathrm{hPa}$ with some saturation at the top of the boundary layer, suggesting the presence of low-level clouds. Aloft, there is some indication of a relatively moist-free troposphere, with possibly cirrus clouds close to the tropopause. The three model runs tested here also show an inversion and saturation in the boundary layer and a fairly moist atmosphere aloft, albeit without saturation near the tropopause (Figs. 6b-d). Overall, at this time (prior to the frontal passage), these simulations are consistent with each other and similar to the observations.

Soon after the cold front has passed (i.e., 2330 UTC 24 December 2015 in observations), the inversion in the lower troposphere has weakened, although there might be some indication of a cold front inversion near $750 \mathrm{hPa}$ (Fig. 6e). There is still saturation below $800 \mathrm{hPa}$, while the upper levels are much drier than $12 \mathrm{~h}$ before. Compared to the observations, the different domain sizes reveal a divergence in simulating the vertical structure (Figs. 6f-h). The $50 \times 50$ domain profiles (Fig. 6f) show no saturation at low levels, but both the $100 \times 100$ and $150 \times 150$ do, although the $100 \times 100$ run (Fig. $6 \mathrm{~g}$ ) suggests a much deeper cloud, and the $150 \times 150$ (Fig. 6h) suggests a shallower cloud than observed. Above $700 \mathrm{hPa}$, both the $100 \times 100$ and $150 \times 150 \mathrm{do}-$ main profiles are more realistic than the $50 \times 50$ run, although the $150 \times 150$ is more realistic below $400 \mathrm{hPa}$, while the $100 \times 100$ run is more realistic above. If the inversion observed at $750 \mathrm{hPa}$ is somewhat simulated, it is at least $100 \mathrm{hPa}$ lower for the $150 \times 150$ domain (Fig. 6h).

During the post-cold-frontal period $12 \mathrm{~h}$ after the front has passed, the observations (Fig. 6i) still indicate low-level clouds, more or less between 900 and $800 \mathrm{hPa}$, but suggest a much lower tropopause around $400 \mathrm{hPa}$ than the previous sounding. This is presumably caused by the presence of a potential vorticity anomaly, which can be seen in the ERA-Interim (not shown). The three 

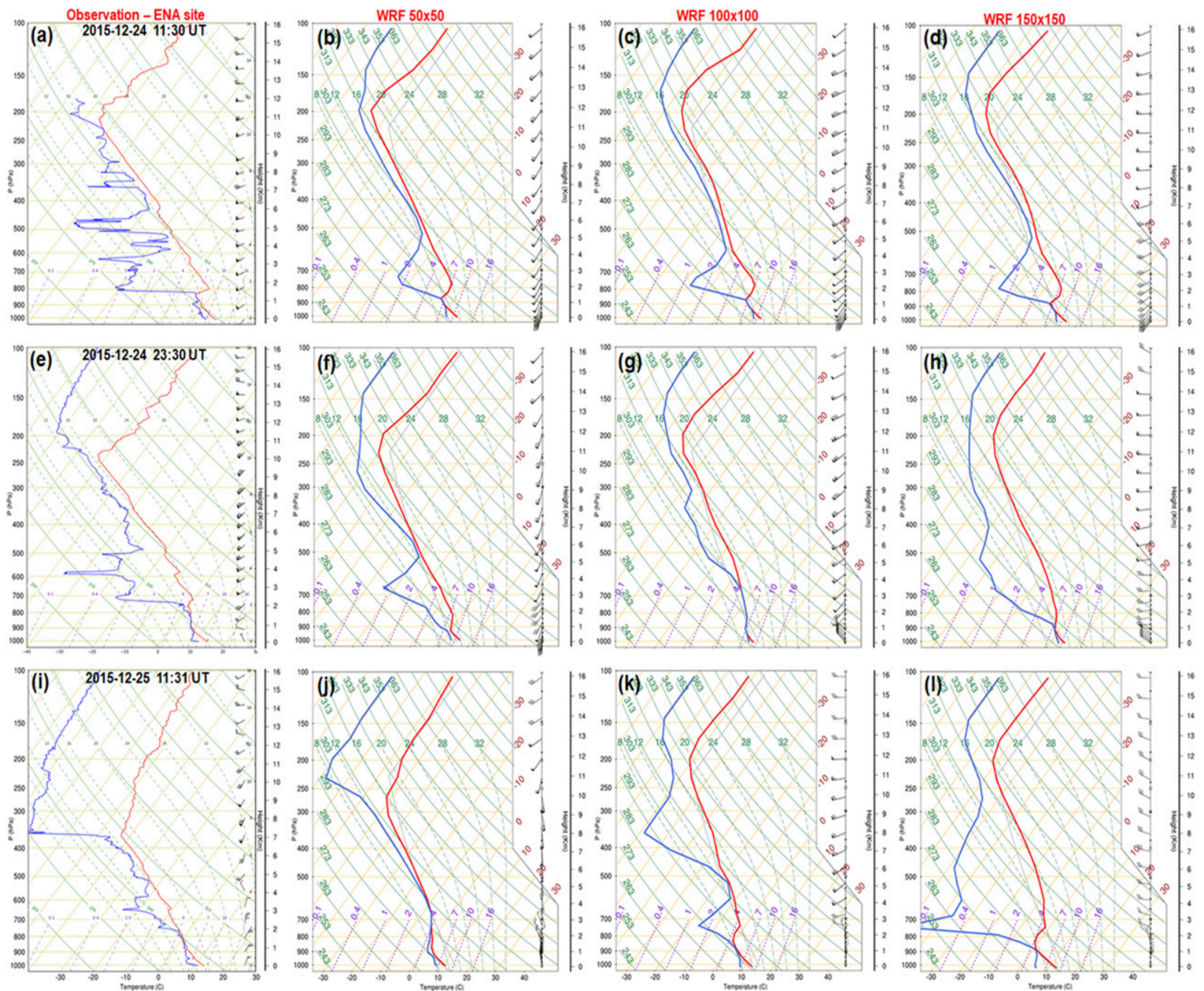

FIG. 6. Skew $T-\log p$ diagrams for the December case over the ENA site at (a) 1130 and (e) 2330 UTC 24 Dec, and (i) 1131 UTC 25 Dec 2015 from radiosonde launched at the ENA. (b),(f),(j) As in (a),(e),(i), but from WRF $50 \times 50$; (c),(g),(k) as in (a),(e),(i), but from WRF $100 \times 100$; and (d),(h),(i) as in (a),(e),(i), but from WRF $150 \times 150$ domain sizes. Profiles of temperature (solid red line) and dewpoint temperature (solid blue line). For each altitude, the wind barbs are shown to the right of each plot. Isobars (hPa): lines in the horizontal (solid light brown). Isotherms $\left({ }^{\circ} \mathrm{C}\right.$ ): straight lines (solid light brown) at $45^{\circ}$ angle that increase from the top-left to the bottom-right corners. Dry adiabats $(\mathrm{K})$ : slightly curved green solid lines. Moist adiabats $(\mathrm{K})$ : green curved dashed lines that increase from bottom left to top right. Mixing ratio $\left(\mathrm{g} \mathrm{kg}^{-1}\right)$ : straight lines (dashed purple) slightly tilted to the right.

domain sizes fail to reproduce this upper-level feature (discussed in section $3 \mathrm{e}$ ), while also diverging at low levels from the observed profiles (Figs. 6j-1).

The passage of the cold front significantly impacts the vertical structure of the atmosphere and more precisely in the boundary layer. After the cold front passage, the vertical atmospheric structure is very sensitive to the domain size and responds differently from one domain size to another. Based on the results from Figs. 4 and 5, only the $50 \times 50,100 \times 100$, and $150 \times 150$ domain sizes are able to simulate the cold front passage at the ENA site with a delay that is accentuated in the smallest domain size $(50 \times 50)$. Based on the evolution of the wind speed, temperature, and boundary layer structure, the $150 \times 150$ domain size best captures the cold front and post-cold-frontal conditions at low levels. The poor performance of large domain sizes might be associated with the model's inability to capture the vertical structure, including having an erroneous inversion and a too-dry midtroposphere.

\section{b. Verification with two additional cases}

To test if the results obtained for the simulations of the December cold front are also true for other cold 

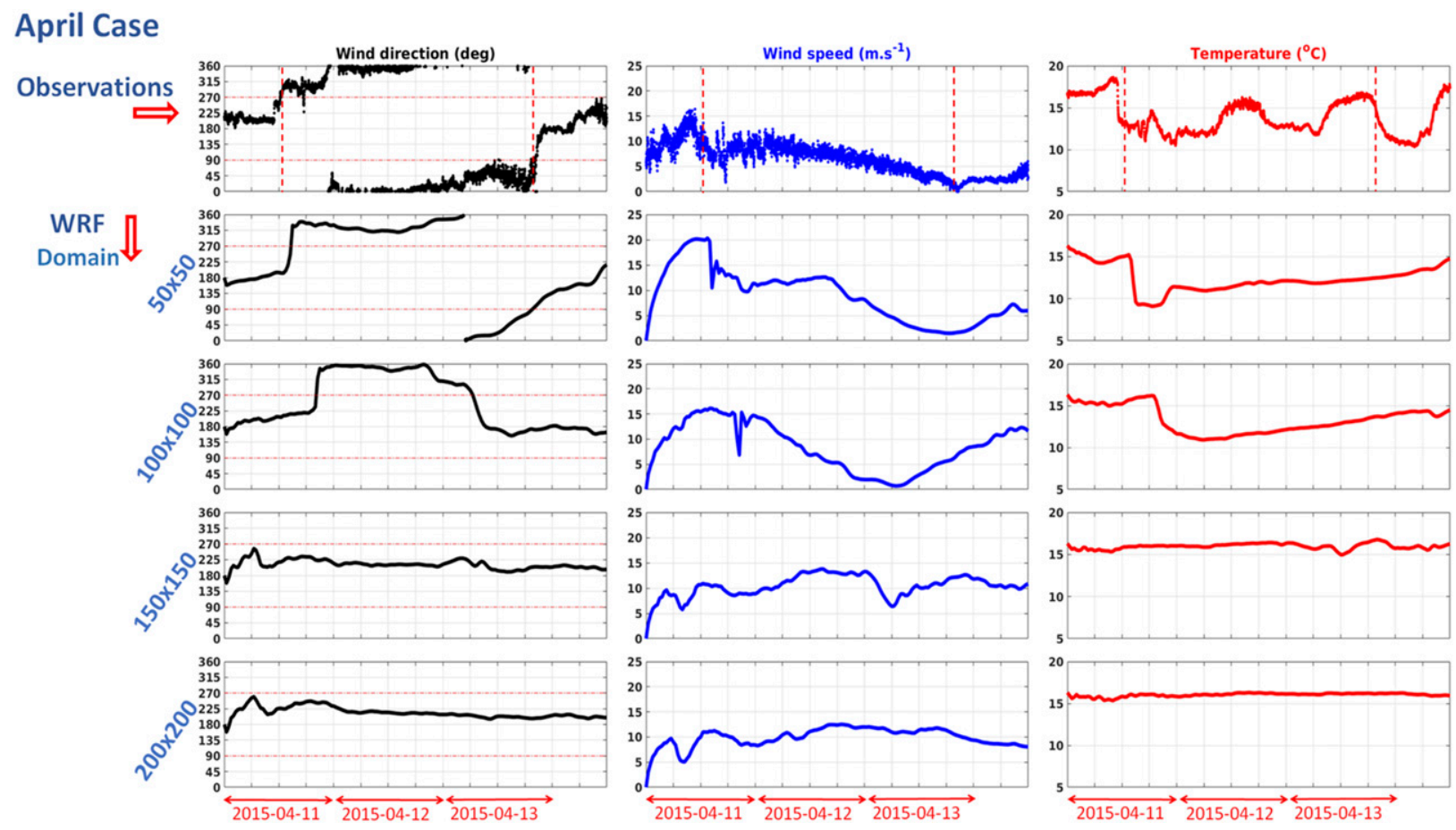

FIG. 7. Time series of (top row) observed and (rows 2-5) simulated (left) wind direction, (middle) wind speed, and (right) temperature at the ENA site for the April 2015 case. The vertical red dashed lines mark the duration of the postfrontal period, and the horizontal dotted lines in the left column the $270^{\circ}$ and $90^{\circ}$ wind direction.

fronts and/or another season, two additional cases are now examined.

Figure 7 shows the evolution of the surface variables in the April case over the ENA site. The observations of wind direction, wind speed, and temperature (Fig. 7, top row) indicate that the cold front reaches the ENA site at 1224 UTC 11 April 2015, and the post-cold-frontal conditions last until 2100 UTC 13 April 2015. The observations indicate that about $3 \mathrm{~h}$ after the passage of the cold front, the wind direction oscillates between northwesterly and northeasterly. The evolution of wind speed shows a linear decrease that starts at the time of the cold front passage until the end of the post-coldfrontal conditions, when it reaches its minimum. Also, the observed temperatures mark the cold front passage with a rapid decrease from $18^{\circ}$ to $12^{\circ} \mathrm{C}$ in the first $2 \mathrm{~h}$.

For this April cold front case, only the $50 \times 50$ and $100 \times 100$ domain sizes capture the passage of a cold front according to the wind direction time series (Fig. 7, first column). For both domains, the wind direction changes abruptly from $200^{\circ}$ to approximately $360^{\circ}$, and both the wind speed and the temperature drop. In comparison with observations, the $50 \times 50$ domain size shows a delay of approximately $3 \mathrm{~h}$ in wind direction change and temperature drop. The $100 \times 100$ domain size predicts an even larger delay of approximately $6 \mathrm{~h}$ in detecting the cold front passage. The $150 \times 150$ and $200 \times 200$ domain sizes do not indicate the passage of a cold front.

The third case study in the analysis takes place in November. Figure 8 shows the evolution of wind direction, wind speed, and temperature from the observations and WRF simulations during the following three days, 6-8 November 2015. The observations of wind direction, wind speed, and temperature indicate that the cold front passed over the ENA site at 1428 UTC 7 November 2015 and post-cold-front conditions lasted until 0514 UTC 8 November 2015. The cold front crosses the ENA site with a wind speed of $10 \mathrm{~m} \cdot \mathrm{s}^{-1}$ and a temperature around $15^{\circ} \mathrm{C}$. These two variables decrease linearly throughout the post-cold-frontal conditions to reach their minimum values of approximately $1 \mathrm{~m} \cdot \mathrm{s}^{-1}$ and $13^{\circ} \mathrm{C}$, respectively, before rebounding again after the post-cold-front conditions terminate.

Similar to both previous cases, the WRF simulations obtained from the $200 \times 200$ domain size and larger show no evidence of the cold front passage at the site. For this November cold front case, the time series of the wind speed and temperature in the $150 \times 150$ domain size are in better agreement with observations than the $50 \times 50$ and $100 \times 100$ cases. The $150 \times 150$ domain size also captures the observed linear decrease in wind speed 


\section{November Case}
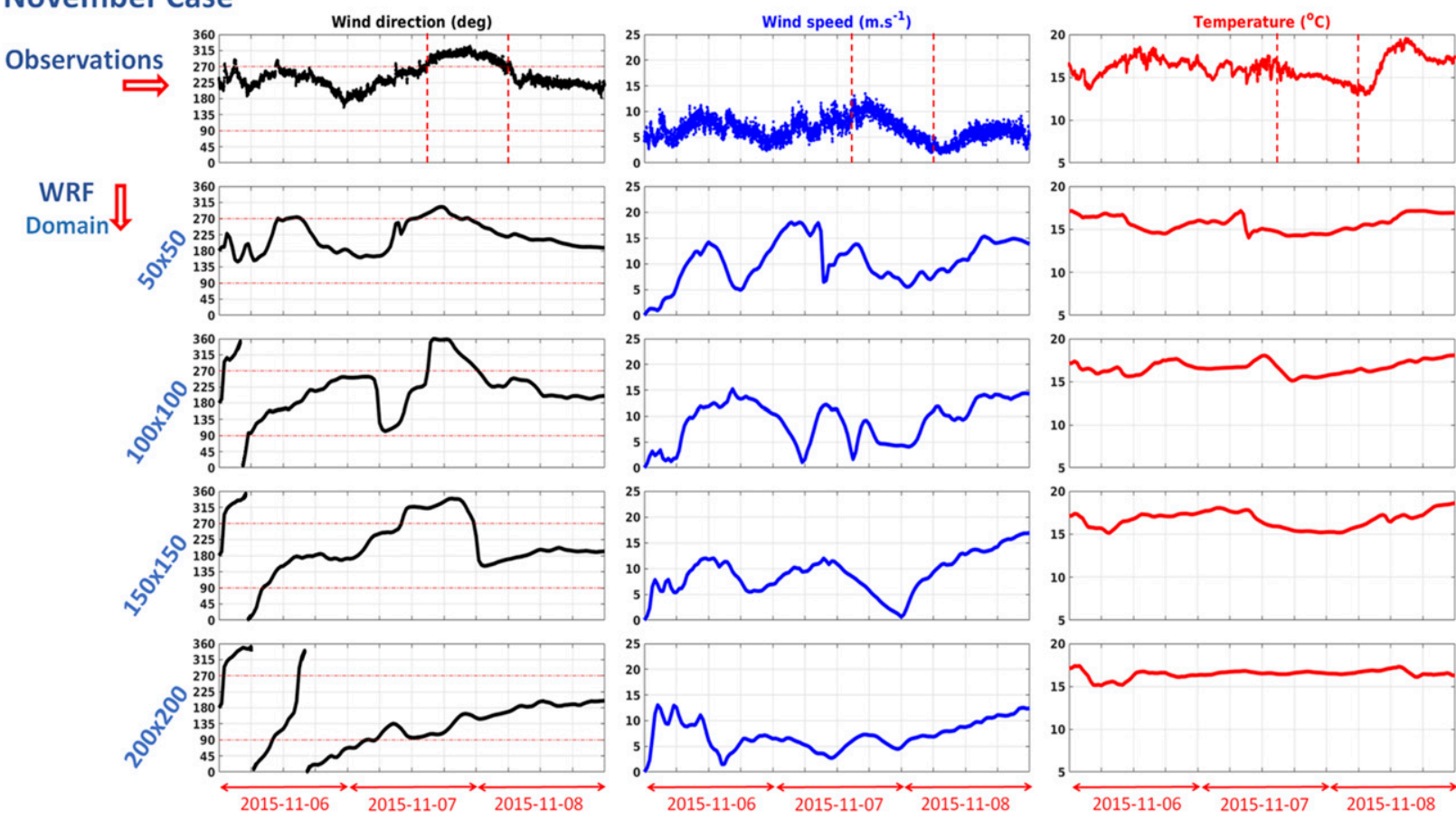

FIG. 8. As in Fig. 7, but for the November 2015 case.

with a rate of $1 \mathrm{~m} \cdot \mathrm{s}^{-1}$ every $2 \mathrm{~h}$. Furthermore, the postcold-frontal temperature and wind conditions are better simulated, compared to the $50 \times 50$ or $100 \times 100$ domain sizes.

These two additional cases confirm the results of the December case and show that the larger $(200 \times 200$ or greater $)$ and smaller $(50 \times 50)$ domain sizes have more biases in simulating a cold front passage over the ENA site, compared to the $100 \times 100$ and $150 \times 150$ domains. For all three cases, the $50 \times 50$ domain size appears to be too restricted to allow WRF to properly handle the coarse-resolution lateral boundary conditions and stabilize (i.e., inadequate spatial spinup), as discussed in Warner et al. (1997). But the causes of errors for the large domain sizes are not so clear. So next, we explore the possible causes for this domain-size sensitivity.

\section{c. Model configuration sensitivity analysis}

We begin our sensitivity tests with an examination of the influence of the downscaling ratio on the cold front simulations. Here, the large-scale driving input from ERA-Interim has an approximate horizontal grid spacing of $81 \mathrm{~km}$. As mentioned earlier, our study uses an approximate downscaling ratio of 1:4, which results in a horizontal grid spacing of approximately $20 \mathrm{~km}$. According to the WRF documentation, the downscaling ratio can be up to $1: 5$, which corresponds approximately to a grid spacing of $16 \mathrm{~km}$ for the inner domain when initialized with the ERA-Interim. However, the recommended downscaling ratio for WRF is 1:3, which would result in a $27-\mathrm{km}$ grid spacing in the inner domain. So, we conduct WRF simulations with this ratio to explore the impact of using the horizontal grid spacing of 27 instead of $20 \mathrm{~km}$.

Four new simulations of the December case are carried out with the 27-km horizontal grid spacing (Fig. 9). The time series of the simulated near-surface variables over the ENA site are examined for three domain sizes: (i) $50 \times 50$, (ii) $100 \times 100$, and (iii) $150 \times 150$, all three driven with ERA-Interim, and (iv) for the $150 \times 150$ domain size driven by WRF $81-\mathrm{km}$ horizontal grid spacing instead. We note that changing the grid spacing but keeping the same number of grid points as our original simulations results in different overall size of the domain. Thus, for example, in the $150 \times 150$ integration with $27-\mathrm{km}$ grid spacing, the western and northern lateral boundaries are nearly as far from the ENA site as the $20-\mathrm{km}$ grid spacing model with a $200 \times$ 200 domain.

A comparison between the runs with $27-\mathrm{km}$ grid spacing with different domain sizes shows the $50 \times 50$ and $100 \times 100$ domains capture the frontal passage, while the $150 \times 150$ does not (Figs. 9a-c). This sensitivity of the biases with respect to domain size in the $27-\mathrm{km}$ 
${ }_{25}($ a)
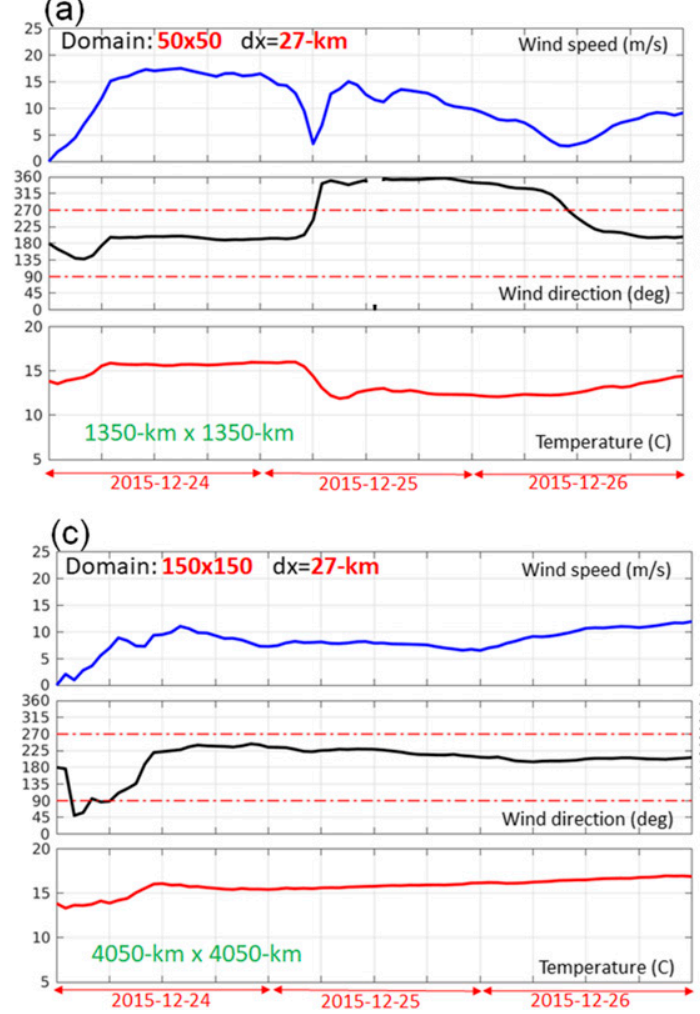

(b)

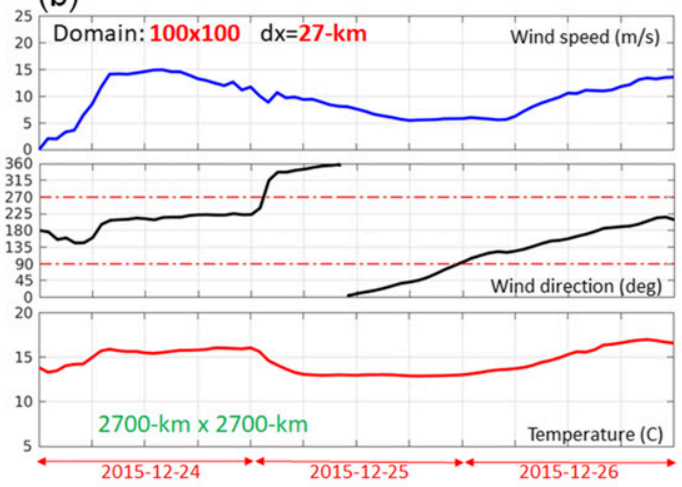

(d) Era-Interim $=>$ WRF $81 \mathrm{~km}=>$ WRF $27 \mathrm{~km}$

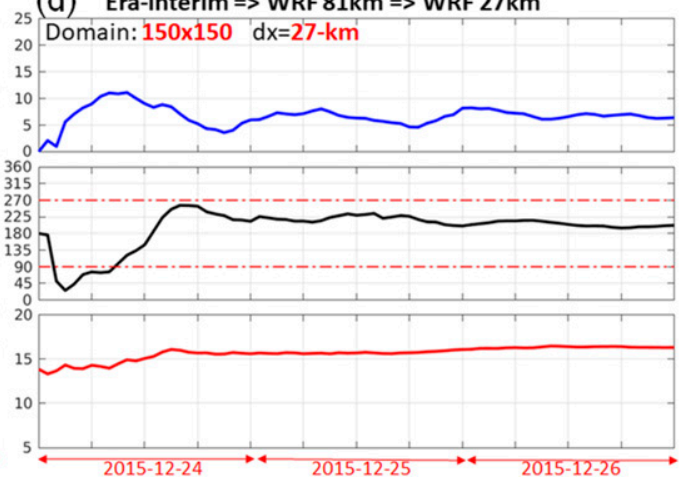

FIG. 9. Time series of the simulated wind speed (blue), wind direction (black), and temperature (red solid) at the ENA site obtained from WRF with horizontal grid spacing of $27-\mathrm{km}$ (a) $50 \times 50$ domain size, (b) $100 \times 100$ domain size, (c) $150 \times 150$ domain size, and (d) $150 \times 150$ domain size driven by WRF $81-\mathrm{km}$ horizontal grid spacing. (December 2015 case). The horizontal dot-dash red lines in the wind direction plots mark directions of $90^{\circ}$ and $270^{\circ}$.

models is consistent with that found in the $20-\mathrm{km}$ models (i.e., Fig. 5). Comparing the results for a set of different domains suggests that the impact of changing the downscaling ratio from approximately $1: 4$ to $1: 3$ is mainly related to the distance between the model lateral boundaries and the ENA site.

Next, for the $27-\mathrm{km}$ grid spacing model with a $150 \times$ 150 domain, we test if one-way nesting the domain inside an $81-\mathrm{km}$ grid spacing domain (rather than forcing it directly with ERA-Interim) reduces the bias. We chose one-way rather than two-way nesting because we want to prevent the child domain from influencing the incoming lateral boundary conditions. With this approach, we aim to test the impact of the downscaling initiated from WRF at $81 \mathrm{~km}$ on integration. However, nesting does not change the result: the $150 \times 150$ domain for $27 \mathrm{~km}$ still does not generate a cold frontal passage at the ENA site (Fig. 9d). Thus, it appears that the bias in the larger domains is not related to a lack of nesting or a downscaling ratio issue.

Here, we summarize two additional configuration tests that had minimal impact, and as such, no figures are included for these results. Integrations for the December case were initialized at 24 and $48 \mathrm{~h}$ earlier to test for spinup issues. No significant changes were found in the overall results for those integrations. Therefore, the biases discussed herein are highly unlikely to be initial conditions spinup related. To test if vertical grid spacing is impacting the results, for domains of $150 \times 150$ and $300 \times 300$ size, the December case was integrated using 30 vertical levels instead of 41 . This change also had minimal impact on the simulation of the frontal passage.

The final configuration analysis examines the sensitivity to the distance between the site and the model boundary. One prerogative of our current study and analysis is that the ENA site should be located in a manner that allows the model to capture a large area undergoing post-cold-frontal conditions (i.e., to the west of the site). This site-centered domain configuration automatically imposes the distance between the forcing and the site (i.e., the larger the domain, the farther away the site is from the initial and boundary conditions). However, the synoptic flow for these cold fronts has a strong northwesterly component aloft, so the distance 
(a) Domain: $300 \times 300$ Shifted to the East

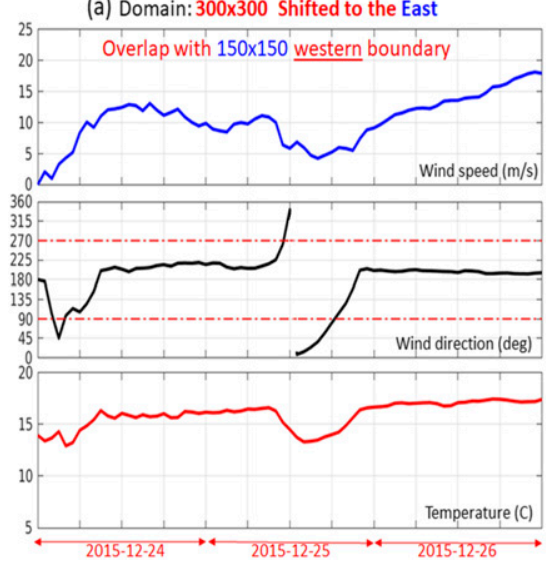

(b) Domain: $300 \times 300$ Shifted to the South

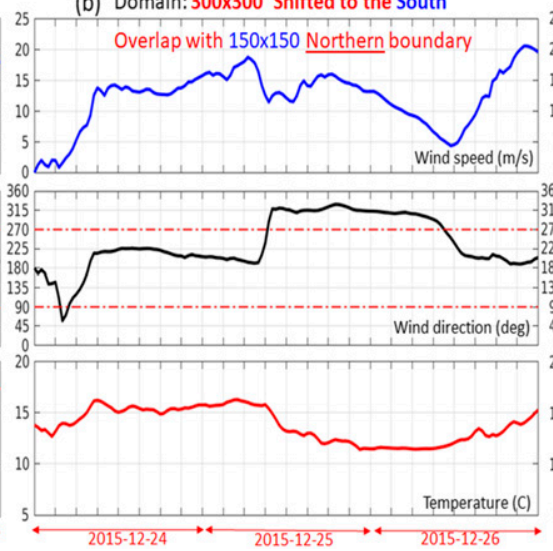

(c) Domain:300x300 Shifted to the Southeast 20 - Overlap with $150 \times 150$ Northern and Western boundaries

FIG. 10. Time series of the simulated wind speed (blue), wind direction (black), and temperature (red solid) at the ENA site obtained from WRF with horizontal grid spacing of $20 \mathrm{~km}$ shifted $300 \times 300$ domain size: (a) to the east to overlap with $150 \times 150$ domain western boundary, (b) to the south to overlap with $150 \times 150$ domain northern boundary, and (c) to the southeast to overlap with the $150 \times 150$ domain northern and western boundary (December 2015 case). The horizontal dot-dash red lines in the wind direction plots mark directions of $90^{\circ}$ and $270^{\circ}$.

from the model boundary to the site presumably has some impact on the model skill at capturing the cold front. Therefore, the second step in this sensitivity analysis on the geometry of the simulations is to check whether the performance of each domain size depends on the location of the site within the domain. For this, we use the $300 \times 300$ domain size and move the domain relative to the site. First, the $300 \times 300$ domain is shifted east so that the western boundary is at the same distance to the site as that of the $150 \times 150$ domain (Fig. 10a); then, it is shifted south to overlap the model's northern boundary with that of the $150 \times 150$ domain size (Fig. 10b); and finally, the entire $300 \times 300$ domain is shifted to the southeast (Fig. 10c) to collocate its northern and western boundaries with the northern and western boundaries of the $150 \times 150$ domain size.

When examining the modeled time series of the wind speed, wind direction, and temperature at the ENA site, a domain shift to the south (Fig. 10b) brings a more significant improvement to the passage of the cold front at the ENA site, compared to a shift to the west (Fig. 10a). This suggests the cold front simulation at the site has a larger sensitivity to northerly flow, compared to westerly flow. Finally, combining both changes by shifting the domain to the southeast leads to a simulated cold front passage similar to that obtained with the $150 \times 150$ domain size centered on the ENA site (Fig. 10c). Consequently, the sensitivity to domain size of the WRF skill appears to be mainly related to the distance between the site and the point of entry of the large-scale flow within the simulation domain. Presumably, the $150 \times 150$ domain offers the most realistic simulation because it offers the optimum distance for this case. However, the reason behind this optimum distance or domain-size sensitivity needs to be investigated, and for this, we next conduct a spectral analysis.

\section{d. Spectral analysis}

Previous studies have highlighted the connection between the domain size and spectral energy (e.g., Miguez-Macho et al. 2004). The domain size impacts the transition of energy between scales, and turbulent kinetic energy and its upscale transfer can have a major impact on the divergence of horizontal wind and moisture (Stevens et al. 2002). For mesoscale NWP models with grid spacings between 1 and $20 \mathrm{~km}$ and forecast periods of 1 to 3 days, errors at these scales have sufficient time to propagate upscale (Skamarock 2004). One possible solution to slow the error growth while allowing a large domain size is spectral nudging. According to Miguez-Macho et al. (2004), the spectral nudging of long waves corrects the distortion of the large scales. They suggest applying spectral nudging for downscaling studies with regional models of domain sizes of a few thousand kilometers and larger.

Therefore, a new set of model simulations is carried out to quantify the impact of spectral nudging on reducing large-scale circulation biases. In three separate model integrations, we apply spectral nudging to waves above the boundary layer longer than 1500, 2000, and $3000 \mathrm{~km}$. For each of those, we test two nudging durations [i.e., the first $6 \mathrm{~h}$ (Fig. 11a) and the whole $72 \mathrm{~h}$ (Fig. 11b) of the simulation] and two nudging strengths, which are inversely related to the relaxation times of 5000 (weaker nudging) and $3333 \mathrm{~s}$ (stronger nudging). As with other sensitivity tests, we examine the time 

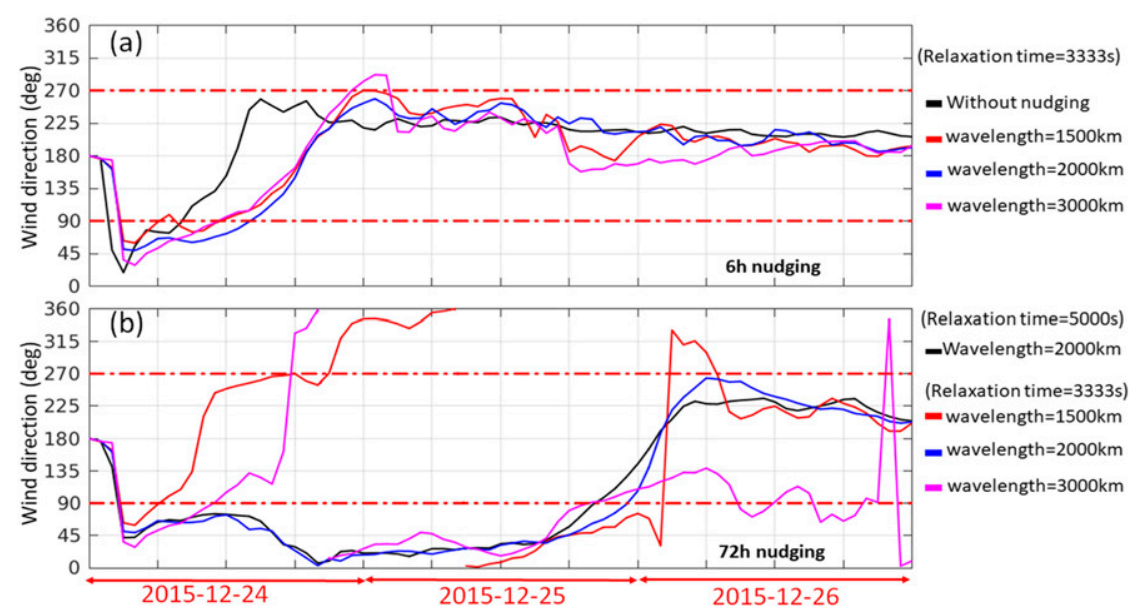

FIG. 11. Time series of simulated wind direction with different spectral nudging conditions: (a) 6-h nudging of wavelengths 1500 (red), 2000 (blue), and $3000 \mathrm{~km}$ (purple) in reference to simulation without nudging (black), and (b) 72-h nudging of wavelengths 1500 (red), 2000 (blue), and $3000 \mathrm{~km}$ (purple) in reference to simulation with $2000-\mathrm{km}$ wavelength nudging and relaxation time of $5000 \mathrm{~s}$ (black), over the ENA site (December 2015 case; domain size: $300 \times$ 300). The horizontal dot-dash red lines mark the wind directions of $90^{\circ}$ and $270^{\circ}$.

series of simulated wind direction derived from the $300 \times 300$ domain size with different spectral nudging conditions over the ENA site.

The brief nudging duration shows a slight improvement in capturing the cold front only with the wavelength of $3000 \mathrm{~km}$, while nudging of wavelength $2000 \mathrm{~km}$ demonstrates the least constraint on the WRF simulation (Fig. 11a). The spectral nudging applied during $72 \mathrm{~h}$ (Fig. 11b) has substantially reduced large-scale biases and enabled capturing the cold front with the 1500- and $3000-\mathrm{km}$ wavelengths for the two relaxation times that are tested. Reducing the strength of the spectral nudging shows no improvement in capturing the cold front passage over the ENA site. Under these prolonged spectral nudging conditions on the $300 \times 300$ domain-size simulation, the timing of the cold front passage is consistent with the detection time found from the simulation of the domain sizes $100 \times 100$ and $150 \times 150$ without spectral nudging (cf. Fig. 5). Thus, spectral nudging appears to be effective in improving large-scale circulation and correcting cold front trajectories, at least for the December cold front case studied here.

In theory, analyzing the spectral energy can provide a confirmation of bias issues. However, as we show below, this sort of analysis can have issues. Using the periodograms of the vertical velocity at the level of $50 \mathrm{~m}$ in the $x$ direction over the entire domain (e.g., Stevens et al. 2002), we calculate the instantaneous one-dimensional kinetic energy power spectra at a fixed time for each of the model configurations. We choose the $50-\mathrm{m}$ level in the periodograms because the observations used in the time series comparison came from the ENA site, which is located at approximately $30 \mathrm{~m}$ above sea level.

In terms of spectral energy, the ranking of domain sizes shown in Fig. 12 is consistent with the performance level of the domain sizes indicated in Fig. 5, and this agrees with previous work (e.g., Skamarock 2004). The models with less power, especially at longer wavelengths (low frequencies), simulate the cold front with more fidelity. The lack of power in the $100 \times 100$ and $150 \times 150$ domains may be associated with slower growth in error. However, the differences in spectral energy relate to more than just the errors in the integration. The larger domains include regions of land, and the orography in these regions impacts the vertical velocity. This results in an increase in the spectral energy. It may be the case that the orography upstream of the ENA site generates errors that propagate downstream, but we cannot discern this from the current analysis. Related to this issue, the spectral energy for the $300 \times 300$ model with a shifted domain is comparable to that of the $300 \times 300$ site-centered domain, despite the opposite being true in terms of the size of the model bias in capturing the cold frontal passage. Thus, we have included this analysis in part to explain some of its limitations. Perhaps most importantly, however, we note that the $150 \times 150$ domain has lower spectral energy than the $50 \times 50$ domain. Both of these domains do not have issues with orography impacting the periodograms, and, as shown above, the $150 \times 150$ domain has a better simulation of the cold front passage. 


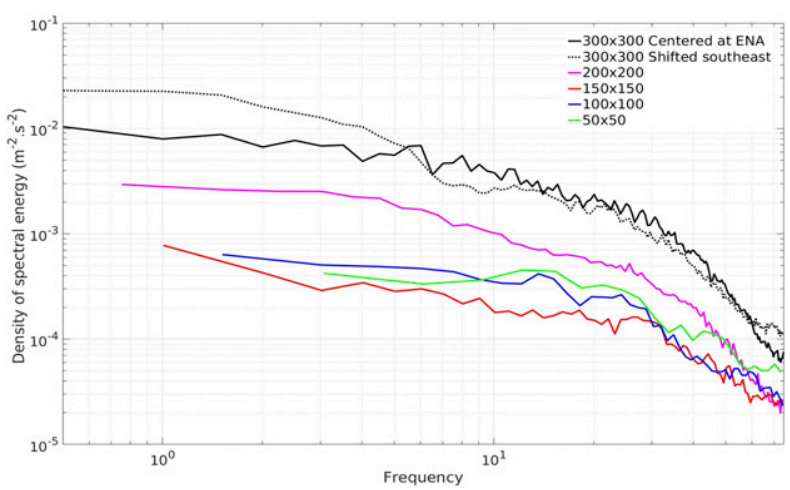

FIG. 12. Normalized spectral energy ( $y$ axis) vs normalized frequency ( $x$ axis) for the December 2015 case after $25 \mathrm{~h}$ starting at 0000 UTC 24 Dec 2015 for five domain sizes centered on the ENA site: $50 \times 50$ (green), $100 \times 100$ (blue), $150 \times 150($ red), $200 \times 200$ (magenta), and $300 \times 300$ (black). The dashed line shows the energy spectrum for the $300 \times 300$ domain that has been shifted to the southeast.

\section{e. Upper-level circulation}

Up to now, we focused on the WRF skill at the surface, but one other source of errors in the model and, in particular, in the larger domains, might be errors at upper levels (e.g., Hakim 2003; Langland et al. 2002; Anwender et al. 2008; Davies and Didone 2013). First, we note that the cold fronts in all three cases are associated with propagating synoptic systems (not shown). Because of the speed of the systems and the length of time of the integrations, we do not believe these model simulations include significant error propagation downstream due to Rossby wave packets. However, the skew $T-\log p$ diagrams show large disparities above $400 \mathrm{hPa}$ between the radiosoundings and model (Fig. 6): the observations show a shallow tropopause in the sounding just after the front passed, and the models do not capture this. Thus, there is definitely a model bias in the upper-level flow.

Near the time of its passage over the ENA site, the cold front for the December case had ample support aloft, as indicated by the strong zonal gradient in the 300-hPa meridional winds (Fig. 13a). A separate examination of pressure on the surface where potential vorticity is equal to $2 \times 10^{-6} \mathrm{~m}^{2} \mathrm{~s}^{-1} \mathrm{~K} \mathrm{~kg}^{-1}$ in the reanalysis affirms that all three cases had strong upper-level support (not shown). The simulated $300-\mathrm{hPa}$ meridional winds (hereafter V300) in the $150 \times 150$ domain capture the zonal gradient; however, the representation of the northerly V300 winds west of the cold front is poor (Fig. 13c). Despite this issue, the $150 \times 150$ model captures the spatial distribution of the $10-\mathrm{m}$ meridional winds (hereafter, V10) fairly well (Figs. 13d vs 13b). In the $300 \times 300$ domain that is shifted south and east, the bias in V300 is larger than that of the $150 \times 150$ model (Fig. 13e), and yet it also captures the surface meridional wind field relatively well (Fig. 13f). Taken together, these two models' results suggest that the proximity of the lateral boundary conditions may be compensating for the errors aloft. This also suggests the configuration allows for a disconnect between the upper- and lower-level biases. However, as noted above, even the $150 \times 150$ model had biases with the timing of the frontal passage and issues in representing the duration of the post-cold-frontal conditions. Finally, the $300 \times 300$ site-centered model has

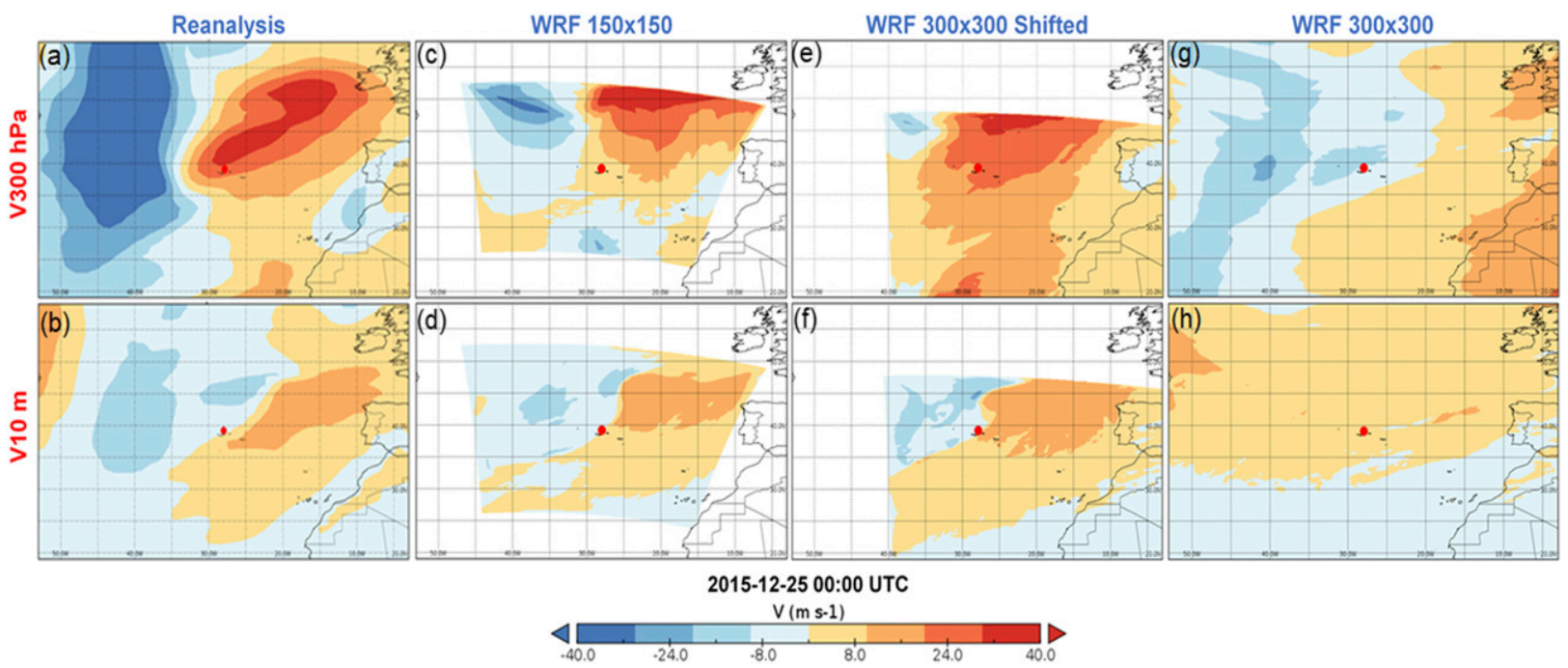

FIG. 13. Two-dimensional maps of the meridional wind centered on the ENA site at (a),(c),(e),(g) $300 \mathrm{hPa}$ and (b),(d),(f),(h) $10 \mathrm{~m}$ at 0000 UTC 25 Dec 2015 from (a),(b) the reanalysis; (c),(d) WRF $150 \times 150$; (e), (f) shifted WRF $300 \times 300$; and (g), (h) WRF $300 \times 300$. The red dot in the center represents the ENA site. 
the largest bias in its V300 field (Fig. 13g) and even worse biases in its surface meridional wind field (Fig. 13h). In this case, the bias in upper-level flow results in a weaker, broader upper-level trough (Fig. 13g), and it follows that the formation of a surface cyclone is not evident in this domain (Fig. 3c). Hence, this model simulation shows no evidence of a cold front at (Fig. 4b) or near the ENA site (Fig. 13h).

We note that a comparison of V300 and V10 between reanalysis and models revealed similar results for the November and April cases: (i) the front had strong upper-level support; (ii) the $150 \times 150$ models captured the region of southerly V300 wind more accurately than the northerly region; and (iii) the $300 \times 300$ case had the largest V300 biases.

\section{Conclusions}

In this study, we sought to produce an adequate WRFbased cold front passage at the ARM ENA site. This work is an initial step in a project aimed at understanding post-cold-frontal cloud physics and using this information to improve climate models. Therefore, the work herein was designed to find the maximum possible domain size (in order to sample the post-cold-frontal conditions over a large simulated area), while also properly capturing the cold frontal passage at the ENA site. To this aim, we explored three case studies to investigate the dependence of cold front passages at a fixed site on (i) the domain size (centered on the site) and (ii) the site positioning with respect to the boundary (the domain is no longer centered on the site). The three cases were selected to be in different seasonsDecember, April, and November 2015-and meant to ensure that the errors we find are not case specific. The results regarding frontal passage sensitivity to domain size and position for the three cases are consistent; however, we acknowledge that this may be because the surface- and upper-level synoptic-scale evolution of these three cold fronts was similar.

We found that domain sizes exceeding $150 \times 150$ grid cells at $20-\mathrm{km}$ grid spacing generate simulations with a bias in the large-scale circulation: the cold front becomes excessively zonal in its orientation and fails to propagate toward the ENA site. Using the $300 \times 300$ gridcell domain for testing, shifting it along three directions (east, south, southeast) with respect to the location of the site revealed a clear sensitivity of the cold front passages to where the site is located, with respect to the boundaries where the large-scale flow enters the domain. Thus, the distance to the ENA site of the regional model's northern and western boundaries appears to be a key parameter to realistically simulate the cold frontal passage. This said, the $50 \times 50$ gridcell domain size captures the cold front passage at the ENA site with a bias in the timing that is larger than that of the $150 \times 150$ domain. The close proximity to the lateral boundaries in the $50 \times 50$ case appears to generate errors due to spatial spinup issues. Sensitivity tests applied to the December case revealed a small impact from spinup time or the vertical grid spacing, while a change of the downscaling ratio from 1:4 to 1:3 meant a change in grid spacing and, consequently, a change in overall domain size. This increased the distance between the northern and western lateral boundaries and caused the $150 \times 150$ domain size at $27 \mathrm{~km}$ to behave like the $200 \times 200$ domain at $20 \mathrm{~km}$.

Applying a prolonged spectral nudging above the boundary layer to waves $1500 \mathrm{~km}$ in length and longer helped the larger domain sizes to generate a more realistic solution. Note that nudging only the longer wavelengths permits the WRF solution in a baroclinic mode to freely develop small-scale variability while redressing the diverted large-scale circulation. Therefore, we interpret the improvement in simulation skill due to nudging longer waves aloft as showing that the circulation biases in the model runs that used large domains are likely caused by accumulated errors in the upper troposphere.

Indeed, an examination of the upper-level circulation in the WRF reveals errors at $300 \mathrm{hPa}$ for all three case studies. The cold fronts show strong upper-level support, and while the $150 \times 150$ and smaller domains can capture the southerly winds accurately, the northerly winds are too weak. In this case, these upper-level deficiencies are compensated by the proximity to the lateral boundary forcing, but in the $300 \times 300$ domain centered on the site, errors are large at both upper and near-surface levels. The model bias in representing upper-level Rossby wave propagation through the domain is an important topic for future research. Given the role of Rossby waves for cyclone formation, the issues identified in our analysis, such as the disconnect between the modeled Rossby wave and cold front propagation, highlight the need for further investigation.

A spectral analysis of model turbulent kinetic energy in the three case studies revealed a sensitivity of the spectral energy to the domain size. For our cases, the quantification of the spectral energy at one vertical level and one time step demonstrates that larger domain sizes and, more specifically, the $300 \times 300$ domain size show more energetic behavior at all scales, compared to smaller domain sizes. This is in part caused by the inclusion of land masses in the large domain, which obscures the actual impact of the growth of errors in the energy spectra. However, for the domain sizes that are small enough to not include orography, the differences 
in spectral energy suggest the magnitude of the biases are consistent with error growth propagating upscale, as in Skamarock (2004).

In three cases, our sensitivity analysis finds that in order to accurately reproduce cold fronts with WRF over the ENA site, either (i) position the site of interest at $1000 \mathrm{~km}$ up to $1500 \mathrm{~km}$ at most from the boundary of dominant inbound flow, or (ii) apply a spectral nudging above the boundary layer for prolonged durations. This said, even with the optimal domain size and/or nudging, the WRF simulations generate cold front passages with a delay, shorter duration, over-or underestimation of meteorological variables, and parameters related to the boundary layer. Furthermore, in addition to the issues in the surface front, the model has biases in the upper-level circulation. However, for these cases, we have found that the surface biases can be reduced more dramatically than the upperlevel biases by adjusting the distance of the lateral boundaries to the site. This provides a recipe for configuring WRF to generate hindcasts that capture surface frontal passages, although more analysis is needed to determine if the upper-level biases translate to issues in properties such as the modeled cloud field.

Acknowledgments. The research is funded by the U.S. Department of Energy Office of Science Grant DE-SC0016344 as part of the Atmospheric Systems Research program. The ENA datasets were obtained from the ARM archive (http://www.archive.arm.gov/ discovery). The ERA-Interim output used to initiate the WRF Model simulations was downloaded from the ECMWF website (http://apps.ecmwf.int/datasets/data/ interim-full-daily/). Also, the authors thank Rob Wood and Jayson Stemmler from the University of Washington for the data from the ENA site browser (http:// ena-data.site/). The authors are grateful to three anonymous reviewers and the editor, whose comments and questions helped significantly improve this manuscript.

\section{REFERENCES}

Anwender, D., P. A. Harr, and S. C. Jones, 2008: Predictability associated with the downstream impacts of the extratropical transition of tropical cyclones: Case studies. Mon. Wea. Rev., 136, 3226-3247, https://doi.org/10.1175/2008MWR2249.1.

ARM, 1993: Balloon-borne sounding system (SONDEWRPR), 2009-2017, eastern North Atlantic (ENA/GRW) Graciosa Island, Azores, Portugal (C1). Atmospheric Radiation Measurement (ARM) Climate Research Facility data archive, https://doi.org/10.5439/1150271.

_ 2 2013: Surface meteorological instrumentation (MET), 2009-2010, 2013-2017, eastern North Atlantic (ENA/GRW) Graciosa Island, Azores, Portugal (C1). Atmospheric Radiation Measurement (ARM) Climate Research Facility data archive.
Bodas-Salcedo, A., K. D. Williams, P. R. Field, and A. P. Lock, 2012: The surface downwelling solar radiation surplus over the Southern Ocean in the Met Office model: The role of midlatitude cyclone clouds. J. Climate, 25, 7467-7486, https://doi.org/ 10.1175/JCLI-D-11-00702.1.

— , and Coauthors, 2014: Origins of the solar radiation biases over the Southern Ocean in CFMIP2 models. J. Climate, 27, 41-56, https://doi.org/10.1175/JCLI-D-13-00169.1.

Bretherton, C. S., and Coauthors, 2004: The epic 2001 stratocumulus study. Bull. Amer. Meteor. Soc., 85, 967-978, https://doi.org/ 10.1175/BAMS-85-7-967.

Davies, H. C., and M. Didone, 2013: Diagnosis and dynamics of forecast error growth. Mon. Wea. Rev., 141, 2483-2501, https:// doi.org/10.1175/MWR-D-12-00242.1.

Dee, D. P., and Coauthors, 2011: The ERA-Interim reanalysis: Configuration and performance of the data assimilation system. Quart. J. Roy. Meteor. Soc., 137, 553-597, https://doi.org/ 10.1002/qj.828.

de Roode, S. R., P. G. Duynkerke, and H. J. J. Jonker, 2004: Largeeddy simulation: How large is large enough? J. Atmos. Sci., 61, 403-421, https://doi.org/10.1175/1520-0469(2004)061<0403: LSHLIL $>2.0 . \mathrm{CO} ; 2$

Dudhia, J., 1989: Numerical study of convection observed during the Winter Monsoon Experiment using a mesoscale twodimensional model. J. Atmos. Sci., 46, 3077-3107, https://doi.org/ 10.1175/1520-0469(1989)046<3077:NSOCOD>2.0.CO;2.

Field, P. R., A. Gettelman, R. B. Neale, R. Wood, P. J. Rasch, and H. Morrison, 2008: Midlatitude cyclone compositing to constrain climate model behavior using satellite observations. J. Climate, 21, 5887-5903, https://doi.org/10.1175/2008JCLI2235.1.

Gelaro, R., and Coauthors, 2017: The Modern-Era Retrospective Analysis for Research and Applications, version 2 (MERRA-2). J. Climate, 30, 5419-5454, https://doi.org/10.1175/JCLI-D-16-0758.1.

Giorgi, F., and L. O. Mearns, 1999: Introduction to special section: Regional climate modeling revisited. J. Geophys. Res., 104, 6335-6352, https://doi.org/10.1029/98JD02072.

Goswami, P., H. Shivappa, and S. Goud, 2012: Comparative analysis of the role of domain size, horizontal resolution and initial conditions in the simulation of tropical heavy rainfall events. Meteor. Appl., 19, 170-178, https://doi.org/10.1002/met.253.

Hakim, G. J., 2003: Developing wave packets in the North Pacific storm track. Mon. Wea. Rev., 131, 2824-2837, https://doi.org/ 10.1175/1520-0493(2003)131<2824:DWPITN>2.0.CO;2.

Hong, S.-Y., and H.-L. Pan, 1996: Nonlocal boundary layer vertical diffusion in a medium-range forecast model. Mon. Wea. Rev., 124, 2322-2339, https://doi.org/10.1175/1520-0493(1996)124<2322: NBLVDI>2.0.CO;2.

—, Y. Noh, and J. Dudhia, 2006: A new vertical diffusion package with an explicit treatment of entrainment processes. Mon. Wea. Rev., 134, 2318-2341, https://doi.org/10.1175/MWR3199.1.

IPCC, 2013: Climate Change 2013: The Physical Science Basis. Cambridge University Press, 1535 pp., https://doi.org/10.1017/ CBO9781107415324.

Jakob, C., 2010: Accelerating progress in global atmospheric model development through improved parameterization: Challenges, opportunities, and strategies. Bull. Amer. Meteor. Soc., 91, 869-876, https://doi.org/10.1175/2009BAMS2898.1.

Janowiak, J. E., V. J. Dagostaro, V. E. Kousky, and R. J. Joyce, 2007: An examination of precipitation in observations and model forecasts during NAME with emphasis on the diurnal cycle. J. Climate, 20, 1680-1692, https://doi.org/10.1175/JCLI4084.1.

Jiménez, P. A., J. Dudhia, J. F. González-Rouco, J. Navarro, J. P. Montávez, and E. García-Bustamante, 2012: A revised scheme 
for the WRF surface layer formulation. Mon. Wea. Rev., 140, 898-918, https://doi.org/10.1175/MWR-D-11-00056.1.

Kain, J. S., 2004: The Kain-Fritsch convective parameterization: An update. J. Appl. Meteor., 43, 170-181, https://doi.org/ 10.1175/1520-0450(2004)043<0170:TKCPAU > 2.0.CO;2.

Kanaros, K. B., I. Bhatti, L. A. McMurdie, and G. W. Petty, 1989: Identification of atmospheric fronts over the ocean with microwave measurements of water vapor and rain. Wea. Forecasting, 4, 449-460, https://doi.org/10.1175/15200434(1989)004<0449:IOAFOT>2.0.CO;2.

Langland, R. H., M. A. Shapiro, and R. Gelaro, 2002: Initial condition sensitivity and error growth in forecasts of the 25 January 2000 East Coast snowstorm. Mon. Wea. Rev., 130, 957-974, https:// doi.org/10.1175/1520-0493(2002)130<0957:ICSAEG >2.0.CO;2.

Lindsay, R., M. Wensnahan, A. Schweiger, and J. Zhang, 2014: Evaluation of seven different atmospheric reanalysis products in the Arctic. J. Climate, 27, 2588-2606, https://doi.org/10.1175/ JCLI-D-13-00014.1.

Medeiros, B., B. Stevens, I. M. Held, M. Zhao, D. L. Williamson, J. G. Olson, and C. S. Bretherton, 2008: Aquaplanets, climate sensitivity, and low clouds. J. Climate, 21, 4974-4991, https:// doi.org/10.1175/2008JCLI1995.1.

Miguez-Macho, G., G. L. Stenchikov, and A. Robock, 2004: Spectral nudging to eliminate the effects of domain position and geometry in regional climate model simulations. J. Geophys. Res., 109, D13104, https://doi.org/10.1029/2003JD004495.

Mioche, G., O. Jourdan, M. Ceccaldi, and J. Delanoë, 2015: Variability of mixed-phase clouds in the Arctic with a focus on the Svalbard region: A study based on spaceborne active remote sensing. Atmos. Chem. Phys., 15, 2445-2461, https://doi.org/10.5194/acp-15-2445-2015.

Mlawer, E. J., S. J. Taubman, P. D. Brown, M. J. Iacono, and S. A. Clough, 1997: Radiative transfer for inhomogeneous atmospheres: RRTM, a validated correlated-k model for the longwave. J. Geophys. Res., 102, 16663-16682, https://doi.org/10.1029/97JD00237.

Morrison, H., G. Thompson, and V. Tatarskii, 2009: Impact of cloud microphysics on the development of trailing stratiform precipitation in a simulated squall line: Comparison of oneand two-moment schemes. Mon. Wea. Rev., 137, 991-1007, https://doi.org/10.1175/2008MWR2556.1.

Naud, C. M., A. D. Del Genio, M. Bauer, and W. Kovari, 2010: Cloud vertical distribution across warm fronts in CloudSatCALIPSO data and a general circulation model. J. Climate, 23, 3397-3415, https://doi.org/10.1175/2010JCLI3282.1.

_ , J. F. Booth, and A. D. Del Genio, 2014: Evaluation of ERA-Interim and MERRA cloudiness in the Southern Ocean. J. Climate, 27, 2109-2124, https://doi.org/10.1175/JCLI-D-13-00432.1.

$\longrightarrow, \ldots$, and — 2016: The relationship between boundary layer stability and cloud cover in the post-cold-frontal region. J. Climate, 29, 8129-8149, https://doi.org/10.1175/JCLI-D-15-0700.1.

Pedersen, J. G., S. P. Malinowski, and W. W. Grabowski, 2016: Resolution and domain-size sensitivity in implicit large-eddy simulation of the stratocumulus-topped boundary layer. J. Adv. Model. Earth Syst., 8, 885-903, https://doi.org/10.1002/2015MS000572.

Qian, J., and L. Zubair, 2010: The effect of grid spacing and domain size on the quality of ensemble regional climate downscaling over South Asia during the northeasterly monsoon. Mon. Wea. Rev., 138, 2780-2802, https://doi.org/10.1175/2010MWR3191.1.

Rémillard, J., and G. Tselioudis, 2015: Cloud regime variability over the Azores and its application to climate model evaluation. J. Climate, 28, 9707-9720, https://doi.org/10.1175/JCLI-D-15-0066.1.

- P. Kollias, E. Luke, and R. Wood, 2012: Marine boundary layer cloud observations in the Azores. J. Climate, 25, 73817398, https://doi.org/10.1175/JCLI-D-11-00610.1.
Salomonson, V. V., W. L. Barnes, P. W. Maymon, H. E. Montgomery, and H. Ostrow, 1989: MODIS: Advanced facility instrument for studies of the Earth as a system. IEEE Trans. Geosci. Remote Sens., 27, 145-153, https://doi.org/10.1109/36.20292.

Skamarock, W. C., 2004: Evaluating mesoscale NWP models using kinetic energy spectra. Mon. Wea. Rev., 132, 3019-3032, https://doi.org/10.1175/MWR2830.1.

— Research WRF version 3. NCAR Tech. Note NCAR/ TN-475+STR, 125 pp., http://www2.mmm.ucar.edu/wrf/users/ docs/arw_v3.pdf.

Stevens, B., and Coauthors, 2005: Evaluation of large-eddy simulations via observations of nocturnal marine stratocumulus. Mon. Wea. Rev., 133, 1443-1462, https://doi.org/10.1175/MWR2930.1.

Stevens, D. E., A. S. Ackerman, and C. S. Bretherton, 2002: Effects of domain size and numerical resolution on the simulation of shallow cumulus convection. J. Atmos. Sci., 59, 3285-3301, https://doi.org/ 10.1175/1520-0469(2002)059<3285:EODSAN >2.0.CO;2.

Tewari, M., and Coauthors, 2004: Implementation and verification of the unified Noah land-surface model in the WRF Model. 20th Conf. on Weather Analysis and Forecasting/16th Conf. on Numerical Weather Prediction, Seattle, WA, Amer. Meteor. Soc., 14.2a, https://ams.confex.com/ams/84Annual/techprogram/ paper_69061.htm.

Treadon, R. E., and R. A. Petersen, 1993: Domain size sensitivity experiments using the NMC Eta model. Preprints, 13th Conf. on Weather Analysis and Forecasting, Vienna, VA, Amer. Meteor. Soc., 176-177.

Trenberth, K. E., and J. T. Fasullo, 2010: Simulation of present-day and twenty-first-century energy budgets of the Southern Oceans. J. Climate, 23, 440-454, https://doi.org/10.1175/ 2009JCLI3152.1.

van Stratum, B. J. H., and B. Stevens, 2015: The influence of misrepresenting the nocturnal boundary layer on idealized daytime convection in large-eddy simulation. J. Adv. Model. Earth Syst., 7, 423-436, https://doi.org/10.1002/2014MS000370.

Voigt, A., and T. A. Shaw, 2015: Circulation response to warming shaped by radiative changes of clouds and water vapor. Nat. Geosci., 8, 102-106, https://doi.org/10.1038/ngeo2345.

Warner, T. T., R. A. Peterson, and R. E. Treadon, 1997: A tutorial on lateral boundary conditions as a basic and potentially serious limitation to regional numerical weather prediction. Bull. Amer. Meteor. Soc., 78, 2599-2618, https://doi.org/ 10.1175/1520-0477(1997)078<2599:ATOLBC>2.0.CO;2.

Wood, R., 2012: Stratocumulus clouds. Mon. Wea. Rev., 140, 2373 2423, https://doi.org/10.1175/MWR-D-11-00121.1.

_ , and D. L. Hartmann, 2006: Spatial variability of liquid water path in marine low cloud: The importance of mesoscale cellular convection. J. Climate, 19, 1748-1764, https://doi.org/ 10.1175/JCLI3702.1.

_ - and Coauthors, 2015: Clouds, aerosols, and precipitation in the marine boundary layer: An ARM Mobile Facility deployment. Bull. Amer. Meteor. Soc., 96, 419-440, https://doi.org/10.1175/ BAMS-D-13-00180.1.

Xue, Y., R. Vasic, Z. Janjic, F. Mesinger, and K. E. Mitchell, 2007: Assessment of dynamic downscaling of the continental U.S. regional climate using the Eta/SSiB Regional Climate Model. J. Climate, 20, 4172-4193, https://doi.org/10.1175/ JCLI4239.1.

Yamaguchi, T., W. A. Brewer, and G. Feingold, 2013: Evaluation of modeled stratocumulus-capped boundary layer turbulence with shipborne data. J. Atmos. Sci., 70, 3895-3919, https://doi.org/ 10.1175/JAS-D-13-050.1. 